\title{
Hybrid Latex Particles: Preparation with Miniemulsion Polymerization
}

\author{
F.Bouanani ${ }^{1.2}$ \\ ${ }^{1}$ Université d'Oran, Département de Chimie, Oran, Algérie \\ ${ }^{2}$ Ecole Nationale Polytechnique Maurice Audin, Département de Chimie, Oran, Algérie
}

\begin{abstract}
This research developed a novel poly(trifluoropropylmethylsiloxane) (PTMS)/montmorillonite nanoparticles, for technologic applications. PTMS /MMT nanoparticles were prepared by the miniemulsion polymerization method. Montmorillonite clay was encapsulated within a fluorinated cyclosiloxane $(1,3,5-$ tris(trifluoropropylmethyl)cyclotrisiloxane) to give stable water based nanocomposite latex, using miniemulsion polymerization technique. The resulting composite latex was characterized by transmission electron microscopy (TEM), dynamic light scattering (DLS) and RX diffraction. The particles stability was investigated by sedimentation and surface tension measurements. An efficient cationic/nonionic surfactant mixture was used in order to achieve the best compatibility with the monomer. TEM and RX data revealed the partial embedding of montmorillonite in the spherical polymer based nanoparticles. According to DLS measurements, the encapsulated clay particles conserve their size throughout the polymerization process. The melt processing of poly(trifluoropropylmethylsiloxane) matrix to encapsulate the montmorillonite clay was also carried out for comparison purposes.
\end{abstract}

\section{Introduction}

Polymer-clay nanocomposites have received growing attention during the last 20 years since they are knownto display much better physical properties than pure polymers or their classical microcomposites [1]. Several kinds of phyllosillicates have been coated [2,3] with a polymer layer or encapsulated in a polymer matrix [4] to enhance their stability and also to improve their particle distribution at a nanoscale. An appropriate process is crucial in order to achieve this nanocomposite. Several strategies have been considered to prepare polymer silicate nanocomposites which include four main processes: exfoliation-adsorption,in situ polymerization, melt intercalation and template synthesis.Under the first one is also gathered the emulsion polymerization synthesis [5]. The polymer layered phyllosilicate nanocomposite

in the second process is developed by swelling the layered phyllosilicate within the liquid monomer so that the polymer formation can occur in between the intercalated sheets [6]. The melt intercalation enables the layered silicate to mix with the polymer matrix in the molten state but compatibility is required to ensure a thermodynamic stability in the final state [7]. The last technique is the in situ hydrothermal crystallisation of the clay in an aqueous gel medium where the polymer often acts as a template for layer formation [8].

In miniemulsion process, the monomer droplets are protected against the monomer diffusion (Ostwald ripening) by an efficient surfactant or a mixture of two surfactants and also by addition of a hydrophobic compound $[9,10]$ allowing the polymerization to occur mainly inside these nanoreactors.

Furthermore, due to their hydrophobic nature platelet clay can be dispersed within the organic phase, i.e. inside the monomer droplets and stabilize the dispersion provided that chemical compatibility and partial clay exfoliation are achieved. In this work, miniemulsion polymerization through an anionic reaction pathway is successfully used to encapsulate a montmorillonite clay within a fluorinated cyclotrisiloxane, the 1,3,5tris(trifluoropropylmethyl)cyclotrisiloxane (D3F) [1113]. A cationic/ nonionic surfactant mixture which consists of didodecyldimethylammonium bromide (DDDBr) and FSO-100 whose general formula is $(\mathrm{C} 2 \mathrm{H} 4 \mathrm{O}) x(\mathrm{CF} 2) y \mathrm{C} 2 \mathrm{H} 5 \mathrm{FO})$ was employed to stabilize the system. In addition, the melt intercalation strategy was tested from the polymerised D3F, poly(trifluoropropylmethyl)siloxane (PTFPMS) in order to estimate the miniemulsion process efficiency with regards to the classical melt process. Our ultimate goal is to assess silicate dispersion on a nanolength scale.

\section{Experimental}

\subsection{Materials}

Montmorillonite clay whose general formula is $\mathrm{Mx}\left(\mathrm{Al}_{4}-\mathrm{xMgx}\right) \mathrm{Si}_{8} \mathrm{O}_{20}(\mathrm{OH})_{4}$, was purchased from a local 
company (ENOF Maghnia) in Algeria. Prior to employment, an acidified clay form was obtained by shaking the clay in a $0.25 \mathrm{M}$ sulfuric acid solution until saturation was achieved at $95 \circ \mathrm{C}$ with continuous stirring during $6 \mathrm{~h}$. The cation-exchanged clay was recovered by filtration and then suspended in de-ionized water.

The monomer D3F was provided by ABCR Company and its nominal purity was larger than $98 \%$. The surfactants DDDBr and FSO-100 were purchased from Acros Organics and Zonyl respectively, and were 99\% pure. All compounds were used as received. The solvent is de-ionized and bi-distilled water.

\subsection{Characterization}

The determination of particle size and particle size distribution was investigated by dynamic light scattering (DLS) using a Malvern Zetasizer-4 with a fixed incident light angle at $90^{\circ}$.

All samples were diluted when necessary to avoid counter saturation. The latex particle morphology was observed through Philips CM 30 transmission electron microscope (TEM) at a maximum accelerating voltage of $100 \mathrm{kV}$. The samples were prepared by casting a latex solution drop onto a 200-mesh copper grid covered with carbon film. This drop is absorbed on a filter paper no 41 and deeped immediately in liquid ethane cooled with liquid nitrogen, then transferred inside the electron microscope. The incineration experiments were carried out in programmable Forced-Draft furnace (Fisher Scientific Inc.) at $500{ }^{\circ} \mathrm{C}$ for $1 \mathrm{~h}$. The ash weight was taken as the clay weight after subtraction of the adsorbed water weight estimated to be $3.5 \%$ of the initial sample weight.

\section{Table 1:}

\begin{tabular}{ll} 
Miniemulsion basic components and composition & \\
\hline Component & Total $((\mathrm{w} / \mathrm{w}) \%)$ \\
\hline$D_{3}^{\mathrm{F}}$ & 18.0 \\
Montmorillonite & 0.75 \\
DDDBr & 1 \\
FSO100 & 0.5 \\
Water & 76 \\
\hline
\end{tabular}

\section{Results and discussion}

\subsection{Miniemulsion stability}

\subsubsection{Surfactant effect}

The samples were prepared following the typical procedure described above with the basic components shown in Table 1 except that only the nonionic surfactant FSO 100 was incorporated, the cationic surfactant effect being previously described elsewhere [12]. The variation of the average droplet size $(\bar{R})$ before polymerization deduced from DLS as a function of added FSO 100 amount is represented in Fig. 1. It is noticed that at very low concentration or in absence of FSO 100 the droplet size measured is as high as $800 \mathrm{~nm}$. By increasing the FSO 100 concentration up to $0.15 \mathrm{wt} \%$ in the basic recipe, the oily droplet size is reduced down to $350 \mathrm{~nm}$. A further increase of the surfactant content up to $0.3 \mathrm{wt} \%$ does not bring any additional size reduction and a leveling off to a plateau-like step is observed.

It is also interesting to mention that at and above $0.15 \mathrm{wt} \%$ of FSO100 the system shows remarkable stability over several months.

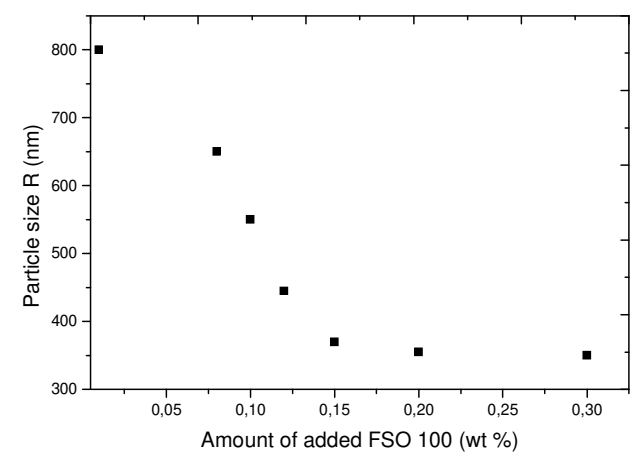

Fig.1. Correlation between particle size and FSO 100 amount added to the aqueous phase before polymerization.

As can be seen from Fig. 2, the particle size change as determined by DLS in the course of the polymerization reaction when combining cationic and nonionic surfactant in optimal proportions as described in Table 1 is minor. This result is consistent with the literature [15] and indicates clearly that a real miniemulsion process has been accomplished. It should be noted that the average $\bar{R}_{\text {has about the same value at that obtained above (see }}$ Fig. 1). This is in good agreement with the results obtained by Qunhui et al. [16] for polystyrene laponite composites synthesized via miniemulsion polymerization using a nonionic/cationic mixture.

\subsubsection{Miniemulsion stability}

The miniemulsion surface tension was measured as a function of time just after sonication as shown in Fig. 3. After $50 \mathrm{~s}$, the surface tension remains relatively constant at about $42 \mathrm{mN} / \mathrm{cm}$. Since this value is well above typical values of micellised surfactant aqueous solutions, it can be ascribed to incomplete covering of the latex particle surface by the surfactant molecules [17]. This observation is an additional support for an effective miniemulsion process occurrence. 


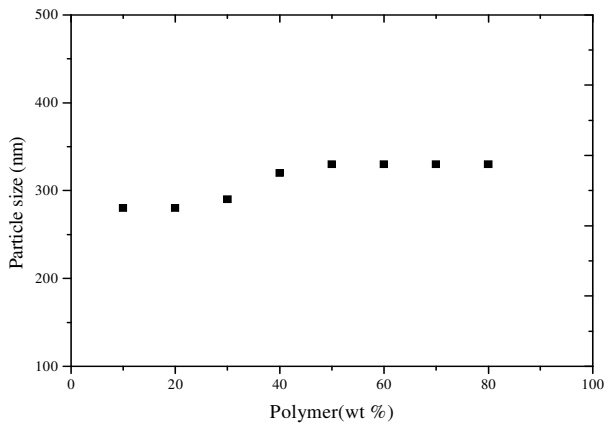

Fig.2. Droplet size evolution during the polymerization reaction.

On the other hand, the constancy for a relatively long time of the surface tension confirms that the nonionic/ cationic surfactant mixture is very efficient in stabilizing the nanocomposite.

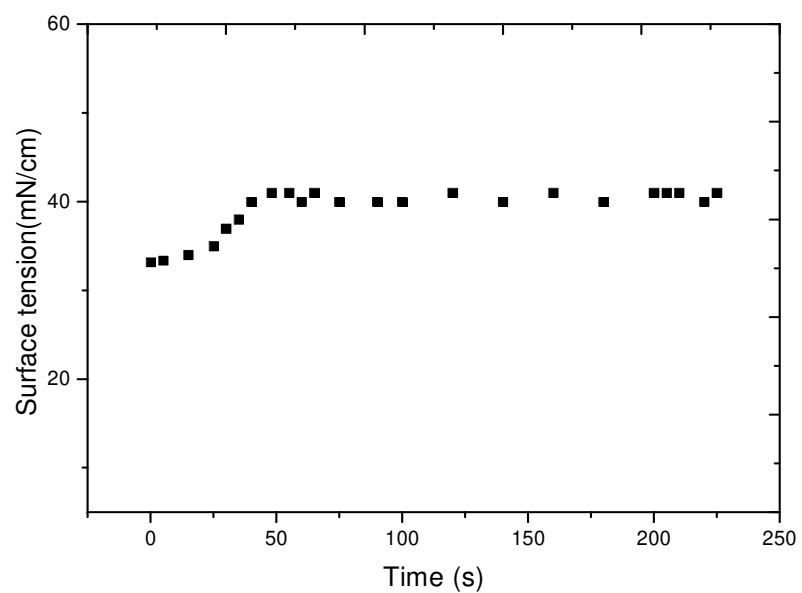

Fig.3. Miniemulsion surface tension time evolution of the $\mathrm{D}_{3} \mathrm{~F}$ miniemulsion.

\subsection{Encapsulation by miniemulsion}

\subsubsection{Preliminaries}

In order to investigate the montmorillonite surface modification efficiency, the clay was stirred with the surfactant in the aqueous phase for $1 \mathrm{~h}$, then the monomer was added under continuous stirring for $24 \mathrm{~h}$. A phase separation was observed after $48 \mathrm{~h}$ of free standing. The aqueous and oily phases were separated and clay distribution in each phase was determined by ash weight measurement after mixture incineration. The obtained results show that $65 \%$ of the clay are located within the monomer layer. This indicates clearly that the surfactants/clay mixture remained primarily in the oily monomer phase under mechanical shear.

\subsection{2. $D L S$}

The monomer and polymer droplet sizes with and without clay added are regrouped in Table 2. The size increase observed upon clay addition is a direct evidence of an effective encapsulation. Indeed, the phyllosilicate hydrophobic nature compatible with the monomer is favourable to the droplet stability. However, the presence of a double population in the montmorillonite polymer sample can be interpreted in terms of a partial encapsulation since some of the particles remain unchanged with regards to their mean size.

Table 2:

Particle size and particle size distribution in the miniemulsions with and without added montmorillonite (from DLS)

\begin{tabular}{llllll}
\hline Miniemulsion & \multicolumn{2}{l}{$\begin{array}{l}\text { Without the } \\
\text { montmorillonite }\end{array}$} & & $\begin{array}{l}\text { With the } \\
\text { montmorillonite }\end{array}$ \\
\cline { 2 - 3 } \cline { 5 - 6 } & $R(\mathrm{~nm})$ & $\begin{array}{l}\text { Standard } \\
\text { deviation }\end{array}$ & & & \\
& & 0.04 & & 276 & $\begin{array}{l}\text { Standard } \\
\text { deviation }\end{array}$ \\
\hline Monomer & 246 & 0.15 & & $R_{1}=330, R_{2}=276$ & 0.19 \\
Polymer & 280 & 0.19 &
\end{tabular}

\subsection{3. $X R D$}

Spectral information on the clay platelet structure can be obtained by XRD analysis [18]. As depicted in Fig. 4 when the pure montmorillonite XRD pattern (I) exhibits one diffraction peak at diffraction angle $2 \theta=5.6^{\circ}$ leading to $\mathrm{d}(001)$ spacing of $13.5 \mathrm{~A}^{\circ}$, the diffraction profile of the acidified montmorillonite (II) is centered at $2 \theta=4.8^{\circ}$ with $\mathrm{d}(001)$ spacing of $18.01 \mathrm{~A}^{\circ}$. The larger latter value is probably due to the presence of two interlamellar water layers, subsequent to the acid treatment and reflects the change in interlayer cations and their associated hydratation states [19].

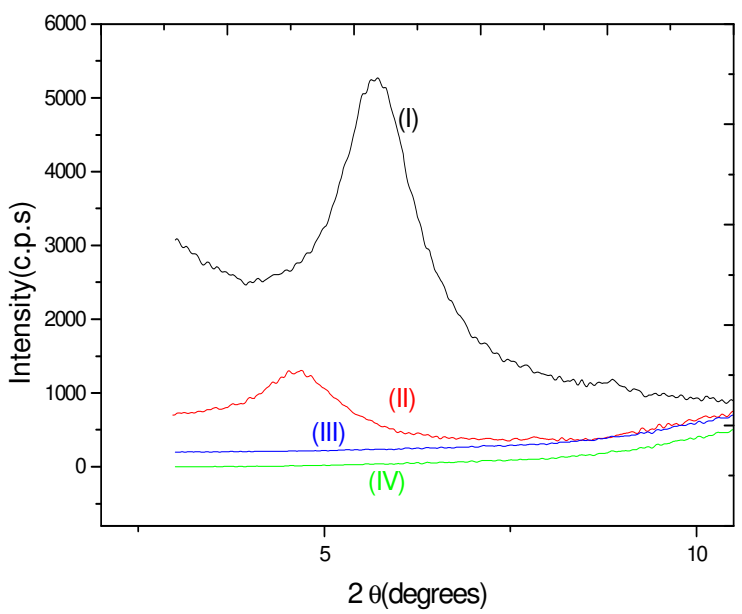

Fig.4. Nanostructure XRD spectra: (I) pure montmorillonite; (II) acidified montmorillonite; (III) nanocomposite before polymerization; nanocomposite after polymerization.

On the other hand, for both nanocomposites in monomer and latex miniemulsions, no apparent diffraction peak could be detected in the whole available diffraction angle range suggesting a fully exfoliated structure of the montmorillonite clay. This result is also due to the fact that DDDBr pre- modified montmorillonite can easily be exfoliated and encapsulated inside the polysiloxane latex, in agreement with the literature [20,21]. 


\subsubsection{TEM analysis}

The structural and composition heterogeneities have been observed by transmission electron microscopy. As seen on the TEM image of the mixed nanocomposite in Fig. 5, most of the particles have a well-defined spherical shape though a small fraction of solid particles co-exist. Hence, the mixed nanocomposite contains both free montmorillonite clay and spherical nanocomposites. In this case, only partial encapsulation is obtained as already deduced from sedimentation data.

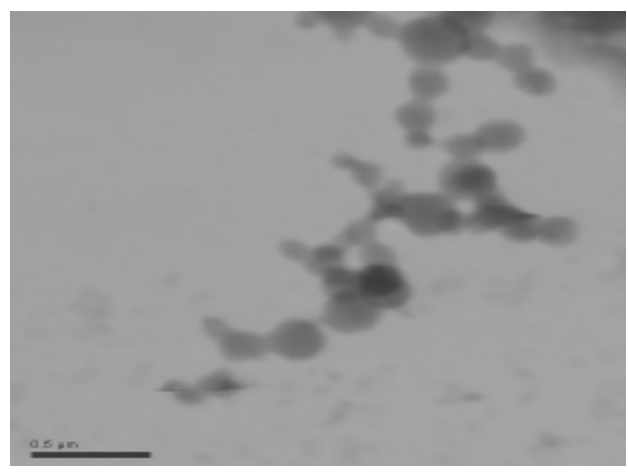

Fig.5. Mixed nanocomposite TEM image

\section{Conclusion}

It was shown by DLS, TEM and RX diffraction that the miniemulsion process leads to an effective encapsulation of montmorillonite. A novel poly(trifluoropropylmethyl)siloxane / montmorillonite hybrid nanoparticle in the form of a water dispersion was developed with up to $5 \mathrm{wt} \%$ clay loading through a miniemulsion polymerization approach. The nanocomposite system obtained in this way was macroscopically homogeneous and stable with clay being embedded within the polymer particles with a fully exfoliated structure. The presence of a cationic/nonionic surfactant mixture together with the sonication process played a cooperative role in stabilizing the miniemulsion.

\section{References}

[1] H. Lu, G.-Z. Liang, X. Ma, B. Zhang, X. Chen, Polym. Int. 531545 (2004).

[2] E.P. Giannelis, R. Krishnamoorti, E. Manias, Adv. Polym. Sci. 107 138 (1999).

[3] T.J. Pinnavaia, G.W. Beall (Eds.), Polymer-Clay Nanocomposites, vol. 1, John Wiley \& Sons, New York, 2000.

[4] M. Zanetti, S. Lomakin, G. Camino, Macromol. Mater. Eng. 279 1$10(2000)$.

[5] M. Alexandre, P. Dubois, Mater. Sci. Eng. 28 1-63 (2000).

[6] Y.W. Luo, X.D. Zhou, J. Polym. Sci., Part A: Polym. Chem. 42 2145-2152 (2004).

[7] M. Alexandre, P. Dubois, T. Sun, J.M. Garces, R. J'erome, Polymer 43 2132-2139 (2002).

[8] R.A. Vaia, E.P. Giannelis, Macromolecules 30 7990-7999 (1997).

[9] K.A. Carrado, L.Q. Xu, Chem. Mater. 101440 (1998).

[10] (a) J. Delgado, M.S. El-Aasser, J.W. Vanderhoff, J. Polym. Sci., Part A: Polym. Chem. 24861 (1986).

(b) J.M. Asua, Prog. Polym. Sci. 27 1283-1386; (2002).

(c) S.T. Wang, F.J. Schork, G.W. Poehlein, J.W. Gooch, J. Appl. Polym.Sci. 60; 2069 (1996).
[11] M. Barr`ere, C. Ma^ıtre, F. Ganachaud, P. Hemery, Macromol. Symp. 151 359-367 (2000).

[12] M. Barr`ere, C. Ma^tre, M.A. Dourges, P. Hemery, Macromolecules 34 (2001) 7276-7280.

[13] F. Bouanani, D. Bendedouch, C. Maitre, J. Teixeira, P. Hemery, Polym. Bull. 55 (6) (2005) 429-436.

[14] A. Yahiaoui, M. Belbachir, J. Appl. Polym. Sci. $100 ; 1681-1687$ (2006).

[15] M. Antonietti, K. Landfester, Prog. Polym. Sci. 27 689-757. (2002).

[16] S. Qunhui, Y. Deng, Z. Lin Wang, Macromol. Mater. Eng. 289 288-295 (2004)

[17] K. Landfester, N. Bechthold, F. Tiarks, M. Antonietti, Macromolecules 322679 (1999).

[18] T.Yui, H.Yoshida, H. Tachibana, D.A. Tryk, H. Inoue, Langmuir 18 891-899 (2002).

[19] A. Harrane, R. Meghabar,M. Belbachir, Int. J. Mol. Sci. 3 790-798 (2002).

[20] Z. Tong, Y. Deng, Polymer 48) 4337. (2007).

[21] Z. Tong, Y. Deng, Ind. Eng. Chem. Res. 452641 (2006). 